thermometers fall at different rates. Observations made simultaneously on them every minute, and plotted on squared paper, illustrate fairly well Kirchhoff's law enunciating that a body emits those rays best which it absorbs best. When the gas flame is replaced by a freezing mixture, the greatest fall of temperature is experienced by the blackened thermometer, and the least by the silvered one, for the same reasons.

The same arrangement of thermometers may be used to show the cold produced by evaporation. For this purpose, the bulb to be blackened has to be wetted immediately before startirig the radiation experiment. First the temperature of this thermometer falls, even though the gas flame be lighted, but after a few ninutes its temperature rises very quickly to reach the same state of equilibrium as when taken with dry black paint. In Fig. I the dotted curve represents the behaviour of the freshly wetted blackened thermometer.

For silvering the thermometer bulbs, we use most successfully the process described first by A. Martin in Poggendorff's Annalen (cxx. 1863, p. 335), and reprinted in many of the books on practical physics.

München (Bavaria), Kgl. Technische Hochschule.

\section{THE TOTAL ECLIPSE OF THE SUN}

THE last total solar eclipse of this century appears to have been successfully observed all along the line of totality. The weather conditions were favourable at all the observing stations, and numerous photographic and visual observations have been made of the phenomena revealed during a total eclipse. Elaborate arrangements were made to study the eclipse in all its aspects, and it has fortunately been possible to carry them out in a most satisfactory manner.

A code telegram received at the Solar Physics Observatory, South Kensington, from Sir Norman Lockyer, states:- "At the time of the eclipse the weather was excellent, and all the instruments were satisfactorily employed. There was a fall in temperature during the eclipse of from $4^{3}$ to $6^{\circ} \mathrm{C}$. The eclipse was not a dark one, and very few stars were seen. The corona exhibited large equatorial extensions and distinct polar tracery as expected. Observations of the shadow band were fully made in two planes. In the fixing up of the instruments, and the making of the observations, assistance was given by about 150 of the officers and crew of H.M.S. Theseus, which conveyed the eclipse party from Gibraltar to Santa Pola, a few miles south-west of Alicante."

The corona was similar to those observed during the eclipses of 1878 and $1889-$-both epochs of sunspot minimum-and thus supplies additional support to the probability of a real connection between the coronal structure and the state of solar activity. There were two long equatorial streamers, the western one being bifurcated and extending about two solar diameters. Several observers note that the inner corona was visible for at least five seconds after totality.

The eclipse was a short, and therefore a bright, one, which accounts for the general report that no shadow was seen either on land or in the atmosphere, and that very few stars were visible. Mercury and Venus were, however, observed. All the reports agree in estimating the duration of totality as shorter than was expected, so that the lunar tables will need slight revision for future computations.

Important observations were made of the shadow bands, which are stated to be very different in many respects from those previously observed. From one of the American stations it is reported that the bands were about one inch in breadth, their general direction being south $56 \frac{1}{2}^{\circ} \mathrm{E}$. ; before totality their motion was at right angles to this-that is, almost north-east; and in the opposite direction after totality. Superposed on the linear bands, however, were certain dark patches pre- viously unnoticed, having a motion at right angles to that of the bands. Baily's beads were well seen at the instants of second and third contact.

Prof. Todd, at Tripoli, is reported to have successfully employed twenty photographic cameras, one of which was furnished with a lens of 24 inches aperture.

The party at Pinehurst, from the U.S. Naval Observatory, under Prof. Skınner, obtained a good series of spectrum photographs, including five with plane and concave gratings and four with an objective prism ; also five large scale photographs of the corona with a lens of forty feet focus..

Prof. Pickering obtained a good series of photographs with the new large instrument he had specially made for searching for an intra-Mercurial planet.

As we go to press, the following description of the observing parties at Santa Pola has been received from Sir Norman Lockyer.

\section{Preparations at Santa Pola.}

Santa Pola, Friday, May 25

The party from the Solar Physics Observatory arrived here on May I7, and now, thanks to the assistance so freely rendered by the Spanish authorities of all grades, and the strong working parties furnished by H.M.S. Theseus, the instruments are all in order and we are ready for the eclipse.

At Gibraltar the Captain of the Theseus sent off Mr. Daniels, torpedo gunner, to meet the Expedition, and the sixty-nine cases of instruments were carefully transferred to a lighter, and so soon as they were landed here those belonging to each instrument were at once brought alongside the piers which had already been erected for them on a site as near the landing stage as possible, thanks to the diligence of $\mathrm{Mr}$. Howard Payn, a volunteer assistant who had preceded the party by rail and had secured the necessary bricks at Alicante.

The prismatic cameras, and those of the ordinary kind, fed by coelostats and siderostats, with all prisms and mirrors, were in adjustment by the 2 rst, and drills were begun on the $22 \mathrm{nd}$.

The parties of observers are as follows; and careful notes of the arrangements made are being kept, as some improvements have been made on those adopted in 1898 . Parties on Shore.-Prismatic cameras. (I) One prism (20 ft.) ; (2) two prisms (7 ft. 6 in.). Coronagraphs. (3) Graham (f. 6.5); (4) Dallmeyer (f. 8.0 about); (5) De la Rue (f. I7.5); (6) long focus (f. 48). (7) Discs. (8) Shadow bands. (9) Meteorology. (IO) Stars. (II) Landscape colours.

Parties on Board.-(I) Stars. (2) Shadow. (3) Meteorology. (4) Landscape.

The whole party is in robust health, thanks to the glorious climate and any amount of work in the open air. We live in a little inn, which since the Queen's birthday has blossomed into the "Victoria Hotel," kept by one Frasquito Dols, a Spanish sailor and sea-cook, a regular "handy man," who has put up mosquito curtains, and rigged up a lift to carry our well-cooked food and excellent local wine to the first floor where we reside; in rooms which, though furnished with unparalleled simplicity, are absolutely clean. It seems a pity that more do not know of this delightful climate so near home, in which the winter months may be so pleasantly spent in the shadow of date palms.

The ship is much further away from the shore than in 1898 -some 2000 yards-and the winds rise very suddenly in the open roadstead. The administration of the camp, therefore, devolves upon Lieut. Doughty, R.N., who, with Lieuts. Andrews and Patrick, remain constantly on shore in a pile-dwelling-a bathing establishment which has seen better days, and has been rechristened "Theseus Villa."

The "Scotch Commission," as it is called here-that is, 
Dr. Copeland's party-has chosen a site up the hill behind the town some distance from the jetty.

Elaborate arrangements have been made for the observation of shadow bands, two walls, E. and W. and N. and S., composed of first-class volley targets $16 \times 6 \mathrm{ft}$., having been erected on a level space which has been whitewashed.

Six discs have been set up on spars, and most careful drills have taken place. I have been quite astonished at the exact reproduction of all the features of a dummy corona set up on each occasion.

It appears that the east wind is the best for us, and it is blowing now ; a cloudy morning generally is followed by a cloudless sky in the afternoon. The weather chances are good, but they are not perfect.

NORMAN LOCKYER.

\section{FIFTY YEARS OF GEOLOGICAL SURVEY IN INDIA.}

THOUGH the Honourable East India Company had showed their interest in the advancement of geological science by the appointment, so long ago as I8I8, of a geologist to the Great Trigonometrical Survey, it is but fifty years since the first "Report of the Geological Survey of India for I848-49," by Dr. John McClelland, was published. In $185 \mathrm{I}$ Dr. McClelland was relieved by Dr. Thos. Oldham, who, on his arrival in Calcutta, found the Geological Survey represented in the capital of India by a room, a box and a messenger. One assistant, Mr. W. Theobald, was already in the employment of the Company, and during the following five years seven assistants were appointed, of whom but Mr. H. B. Medlicott and Dr. W. T. Blanford, names cut deep in the record of Indian geology, survive.

It was not, however, till 1856 that the Geological Survey was established as a regularly organised service, with a sanctioned establishment of superintendent (now styled director), fifteen graded assistants and a palcontologist. In spite of the increased area over which British rule extends, the establishment sanctioned in 1856 remained the same, with some minor, temporary changes, and an alteration of nomenclature, till 1892 , when, instead of an increase, the permanent staff was reduced by three, and to compensate for this reduction arrangements were made for the employment of two "specialists" for terms of years, who were expected to devote their services more especially to economic geology. From one cause and another, this scheme has not received a full trial yet, and it is only during the present year that the full sanctioned staff is at work. The experiments so far made in the temporary employment of assistance to the Geological Survey, for the special purpose of economic work, cannot be regarded as successful, and the result of the present trial will be watched with interest, as it is likely to have great influence in the shaping of the future course and policy of the Survey.

The concrete results of less than half a century's work with this inadequate staff are a geological map of nearly the whole of India proper, which is accurate as regards its main features for this large area, and as regards details for a large proportion of it ; and a considerable acquaintance, largely accompanied by maps, with the mountainous country to the north-west and north, and of the countries to the east, which are included in the Indian Empire. The published results are contained in thirty volumes of the "Records," twenty-nine of the "Memoirs" and twenty volumes, not counting those only partly published, of the "Palceontologia Indica."

Besides this collection of separate memoirs there was prepared, with the approval and sanction of the Government of India, a "Manual of the Geology of India," in two volumes, by Messrs. H. B. Medlicott and W. T.
Blanford, published in 1879 , to which were subsequently added a volume on the "Economic Geology," by the late Dr. Valentine Ball, and one on the "Mineralogy," by Mr. F. R. Mallet. These volumes contained not only much information collected by the Survey, which it had not been possible to publish previously, but for the first time, by collecting scattered information into one general review, made the geology of India generally accessible and intelligible. The need for, and value of, these volumes is shown by the fact that they soon went out of print, and in 1894 a revised version of the first two volumes was issued. The progress of the Survey in the period intervening between these two issues had been so great that a totally different scheme could be adopted, and instead of the series of separate descriptions of isolated areas, which was to a large extent inevitable in I879, it was possible to treat the geology of India as an harmonious whole in 1894 . A re-issue of the third volume of the original edition, the volume on "Economic Geology," has also been commenced, but though nominally a re-issue, it is, even more than in the case of the stratigraphical and structural geology, a new book, being different in scope and in aims, and containing no part of the original work.

The results of the Geological Survey, apart from its publications, are to be looked for both in India and out of it. In India, in the economic development of the Empire; and out of India, in the influence they have had on the advancement of geological science. The former of these is naturally that to which the Adminis. tration attaches the greater importance, and in this connection the existence of the Survey is amply justified in the fact that two of the coal-fields, which yield an important part of the coal-supply of India, were discovered and explored by the Geological Survey. Singarenni, surveyed by Dr. W. King, and Umaria, by Mr. T. W. Hughes, have, from their geographical position, a much greater importance than would appear merely from a numerical statement of the number of tons of coal raised in them, for they serve to supply a large area with cheap fuel which would otherwise be deprived of that advantage. These two fields in themselves would justify the existence of the Survey, from an economic point of view, apart from other benefits; but besides this the existence of a band of trained advisers, and of the observations accumulated by them, has frequently been instrumental in preventing the useless expenditure of large sums of money, and in this way alone the Survey has rendered an ample return for its maintenance.

Though the Administration is naturally most interested in the economic aspects of the work of the Geological Survey, there has never been any attempt to convert it into a mere prospecting or mining department. The Government of India has always recognised purely scientific work as an important duty of the Survey, and regarded the advancement of science not only as a thing to be desired and encouraged on its own account, but as furthering and rendering more valuable the economic results of the Survey, by improving the instrument with which it works. It is this portion of the work of the Survey which is of the greater interest outside India, and more especially to the readers of NATURE.

First among the results which have influenced the course of geological science may be placed the recognition of the importance of deposits formed on land, in which Indian survey took an early and important part. It was shown that the Gangetic alluvium, formerly looked upon as a marine deposit, was, as regards its upper layers at least, a land deposit; it was shown that the great series of sandstones and conglomerates of which the foot-hills of the Himalayas are composed were formed, not in the sea, but on land, by rivers which were the ancestors of those now draining the Himalayas; the great Gondwana system was shown to be exclusively a dry land deposit,

NO. I 596, vOL. 62] 